\title{
Follow-Up of 122 Symptomatic Patients after CABG: Coronary Arteriographic Definition of Disease Progression and Choice of Therapeutic Options
}

\author{
Nasser Hayat Mohamed Zaki Shafie Salah Al-Ghoul \\ M. Thomas Abraham Jiri Endrys \\ Department of Medicine, Faculty of Medicine, Kuwait University, Kuwait
}

\section{Key Words}

Coronary artery bypass graft surgery . Angina. Progression of atherosclerosis . Internal mammary graft

\begin{abstract}
Objective: To examine the graft patency and progression of atherosclerosis $8 \pm 5$ years after coronary artery bypass graft (CABG) surgery in symptomatic patients. The relationship of risk factors to the progression of the disease and the possible degree of anginal relief to repeated postbypass surgery, angioplasty or intensified medical treatment were reviewed. Methods: A retrospective review of medical files and coronary arteriographic studies of 122 consecutive patients who were catheterized from January 1, 1993 to December 31, 1996. Results: At $8 \pm 5$ years after CABG, $44.3 \%$ of saphenous vein grafts had occluded. For the same period, $89.3 \%$ of left internal mammary grafts were
\end{abstract}

\begin{tabular}{ll}
\hline KARGER & (1) 1999 S. Karger AG, Basel \\
Fax +4161306 1234 $34-7571 / 99 / 0081-0058 \$ 17.50 / 0$ \\
$\begin{array}{l}\text { E-Mail karger@karger.ch } \\
\text { www.karger.com }\end{array}$ & $\begin{array}{l}\text { Accessible online at: } \\
\text { http://BioMedNet.com/karger }\end{array}$
\end{tabular}

patent. Diabetes had a better association with progression of disease in native coronary arteries than grafts. Hypercholesterolemia affected the venous graft more. Hypertension inversely affected graft atherosclerosis and to a lesser extent native artery disease progression. Anginal class improved in $91 \%$ of patients having angioplasty. Repeat surgery improved $66 \%$ of the patients. Intensified medical intervention helped $50 \%$ of the group who were not candidates for other interventions. Conclusion: Symptomatic patients with post-CABG have reasonable prognosis. They should be catheterized early. Based on their coronary anatomy and disease burden in their grafted vessels they could benefit from percutaneous transluminal coronary angioplasty (PTCA), repeat CABG or intensive medical treatment. Amongst the three options, those who could have PTCA had better amelioration of their symptoms.
Dr. Nasser Hayat, MD, PhD, FACP, FACC Associate Professor, Department of Medicine Faculty of Medicine, Kuwait University PO Box 24923, Safat 13110 (Kuwait) Fax +9655318454 


\section{Introduction}

Recurrence of angina in patients with previous coronary artery bypass graft surgery $(\mathrm{CABG})$ is an increasing clinical problem. Eighty percent of vein grafts remain patent 5 years after operation $[1,2]$. After the 5 th to the 7th postoperative year there is a progressive increase of atheromatous disease in saphenous vein grafts (SVG). At 10-12 years only $40-60 \%$ of the grafts are not occluded [3]. As grafts occlude and atherosclerosis progresses, $40 \%$ of patients complain of recurrence of angina after 6 years [4]. In a study of 1,117 post-CABG patients, significant graft stenosis appeared on an average of 73 months after surgery [5]. By contrast, 10 or more years after surgery the left internal mammary artery (LIMA) graft to left anterior descending coronary artery (LAD) remains patent in over $90 \%$ of patients. Patency of LIMA to LAD has also been documented 20 years after CABG [6-9]. In this retrospective analysis of symptomatic post-CABG patients, we aim to ascertain the patency of arterial and venous conduits $8 \pm 5$ years following their operation and whether progression of disease in native vessels and grafts is associated with diabetes, hypertension and hypercholesterolemia. In addition, this study attempts to evaluate clinical response following repeat CABG, percutaneous transluminal coronary angioplasty (PTCA) or intensified medical treatment.

\section{Material and Method}

This retrospective study includes 122 consecutive patients with previous CABG who came subsequently for recatheterization. Different surgeons from the UK and USA (mainly Cleveland Clinic) operated on these patients. One third of these patients had their CABG surgery in Kuwait. Coronary bypass surgery started in 1981 in Kuwait with an average mortality of $5.5 \%$. Most of the patients had cold cardioplegia with ST-
Thomas solution. Some (20\%) of the cases had their CABG performed with intermittent ventricular fibrillation technique. Retrograde warm cardioplegia with blood was started 18 months back registering a drop in mortality up to $2 \%$. All patients with previous CABG who were catheterized from January 1, 1993 to December 31, 1996 were included. Cardiac catheterization was done only for symptomatic patients or those with significant silent ischemia. Smoking following $\mathrm{CABG}$, and the presence of diabetes, hypertension and hyperlipidemia were noted by chart review. Use of aspirin and other antianginal drugs was documented. Angina was graded according to the Canadian classification. A significant change of anginal class was reduction of 2 classes whereas reduction of 1 class constituted a positive shift [10]. Results of coronary angiography were carefully assessed by 2 independent observers and were compared to pre-CABG findings.

Progression of lesion was defined as an increased stenosis $\geq 20 \%$ [11-13]. Lesion progression in diabetic, hypertensive and hypercholesterolemic patients was compared with their normal counterparts both for native coronary arteries (NCA) and SVG. Significant differences between percentages were ascertained by $\mathrm{Z}$ equation. Linear regression analysis was used to correlate hypercholesterolemia and disease progression in NCA. Postcatheterization treatment included further intensification in medical treatment, PTCA of culprit lesion(s) or repeat CABG. Patients with diffuse coronary artery disease when symptomatic, despite optimal medical treatment, and who were not candidates for PTCA or repeat CABG, were indicated to undergo transmyocardial laser revascularization. Once patients were assigned a particular treatment plan, they were followed up on an average of $27 \pm 8$ months. In particular, they were monitored for death, congestive heart failure, acute myocardial infarction, or recurrence of angina.

\section{Results}

The clinical characteristics of the total group are given in table 1 . The 23 female patients in the study had a mean age of $60 \pm 8$ years compared to $56 \pm 9$ for males $(\mathrm{p}<$ 0.05 ). The interval from CABG to angiography was 1.5-20 years with a mean of $8 \pm 5$ years. On an average males were catheterized at $8 \pm 5$ years and females at $7.5 \pm 5.5$ years.

Med Principles Pract 1999:8:58-63 
Table 1. Clinical characteristics of 122 patients at post-CABG angiography

\begin{tabular}{lc}
\hline Males, n (\%) & $99(81.1)$ \\
Hyperlipidemia, n (\%) & $108(88.5)$ \\
Diabetes, n (\%) & $59(48.4)$ \\
Hypertension, n (\%) & $59(48.4)$ \\
Mean age, years & $57 \pm 8$ \\
Years after CABG & $8 \pm 5$ \\
\hline
\end{tabular}

Of the total, 58 patients (47.5\%) presented within 6 years of their surgery and 24 patients $(19.7 \%)$ after 12 years. Patients were followed for 8-96 months after their angiography and being assigned to a treatment plan. Both diabetes and hypertension were more prevalent in females (56.5 and $60.9 \%$, respectively) compared to males (46.5 and $45.4 \%$ ). But these differences were not statistically significant. Eighteen patients (15\%) admitted to smoking after CABG. Serum cholesterol levels were normal in 14 patients $(11.5 \%$; $\leq 5.2 \mathrm{mmol} / \mathrm{l}$ ) and elevated in the rest. Adherence to low cholesterol diet or hypercholesterolemic drugs was highly variable among patients and cholesterol levels showed a great scatter over the period of follow-up. Aspirin $(100 \mathrm{mg} /$ day $)$ was used by 112 patients. Seven patients could not tolerate aspirin and were switched to dipyridamole $75 \mathrm{mg}$ t.i.d., and 3 patients stopped using it after the 1st year.

Cardiac catheterization showed the mean left ventricular ejection fraction to be $55 \pm$ $10 \%$. There was a significant progression of the disease for NCA in 97 patients (79.5\%), of which 10 were not hypercholesterolemic. No correlation could be detected for progression of NCA disease and serum cholesterol levels $(\mathrm{r}=0.5)$. Of the 59 diabetic patients, 52 $(88.1 \%)$ showed progression of NCA disease, while only 45 (71.4\%) of the nondiabetic pa- tients showed such progression $(\mathrm{p}<0.05)$. Increased lesion severity in NCA was seen less frequently in hypertensive patients (74.6\%) when compared to nonhypertensives $(84.1 \%$; $\mathrm{p}<0.05$ ).

There were 2.98 grafts per patient. There was a total of 305 SVGs, 56 LIMA grafts and 3 free RIMA grafts. Among the SVGs 135 were occluded $(44.3 \%)$, whereas 50 LIMA grafts were patent $(89.3 \%)$. Of the 3 free RIMA grafts, only 1 was patent.

Occlusion or severe narrowing of SVG could be detected in 1 out of 14 patients (7.1\%) with normal cholesterol level. In contrast 99 out of 108 hypercholesterolemic patients (91.7\%) showed significant stenosis in their venous grafts ( $<<0.05$; table 2$)$. Thirtyfive out of 59 patients $(59.3 \%)$ with hypertension showed SVG occlusion or severe graft stenosis within 6 years, while severe SVG disease was seen in only 25 out of 63 nonhypertensives $(39.7 \% ; p \leq 0.05)$. Presence of diabetes (28 of the 59 patients; $47.4 \%$ ) did not seem to make a difference in the development of graft disease as compared to euglycemia (33 of 63 patients; $52.4 \%$; table 2).

Following catheterization, 24 patients had repeat CABG, 39 underwent PTCA and 59 were assigned to medical treatment. All repeat CABGs were done in Cleveland Clinic. Out of the 24 patients with repeat CABG, 1 died during surgery. Among the 39 patients undergoing PTCA, the procedure was succesful in all. One patient died 2.5 months later and 3 had re-PTCA ( 2 native arteries and 1 SVG graft). Three patients had PTCA of the LAD (1 was dilated through a patent LIMA graft). In the rest PTCA was done for cirumflex or right coronary artery lesions. Stents were used in $40 \%$ of arteries dilated. Improvement was observed in $66 \%$ of the surgical group, $91 \%$ of the PTCA group ( $82 \%$ were asymptomatic with a mean follow-up of 17 months) and 50\% of the medical group. Three patients in the 
Table 2. Progression of atherosclerotic disease process in relation to individual risk factors after $\mathrm{CABG}$

\begin{tabular}{|c|c|c|c|c|c|c|}
\hline & \multicolumn{2}{|c|}{ Hypertension } & \multicolumn{2}{|c|}{ Diabetes } & \multicolumn{2}{|c|}{ Hypercholesterolemia } \\
\hline & yes & no & yes & no & yes & no \\
\hline \multirow{2}{*}{$\begin{array}{l}\text { NCA, } \% \\
\text { p value }\end{array}$} & 74.6 & 84.1 & 88.1 & 71.4 & 80.6 & 71.4 \\
\hline & \multicolumn{2}{|c|}{$<0.05$} & \multicolumn{2}{|c|}{$<0.05$} & \multicolumn{2}{|c|}{ NS } \\
\hline \multirow{2}{*}{$\begin{array}{l}\text { SVG, } \% \\
\text { p value }\end{array}$} & 59.3 & 39.7 & 47.4 & 52.4 & 91.7 & 7.1 \\
\hline & \multicolumn{2}{|c|}{$<0.05$} & \multicolumn{2}{|c|}{ NS } & \multicolumn{2}{|c|}{$<0.05$} \\
\hline
\end{tabular}

medical group needed to have transmyocardial laser revascularization because of severe angina. During the follow-up period no other deaths or congestive heart failure were observed.

\section{Discussion}

Vein graft atherosclerosis is generally a diffuse process and has been correlated with the elevation of serum cholesterol, low high-density lipoprotein cholesterol levels, high serum triglycerides and smoking [13]. Lipid-lowering therapy has been reported to reduce the progression of lesion in both NCA and SVG [14-16]. In this study we could be certain of lipid values at point of entry only. Serial changes in cholesterol for individual patients were not documented. No correlation could be detected in the progress of disease in native vessels among hyperlipidemics and nonhyperlipidemics $(r=0.5)$. However hypercholesterolemia was in excess of $85 \%$ in the total cohort. But in the venous grafts, this correlation was significant as $91.7 \%$ of hyperlipidemics showed significant disease of SVGs, while only $7.1 \%$ of nonhyperlipidemics showed significant graft disease. Graft disease or occlusion could not be ascribed to technical difficulties due to heterogeneity of surgical techniques which bypass conduits. The atherosclerotic process must be different in NCA and SVGs. Others have documented retardatation of the atherosclerotic process in NCA as well as SVG with hypolipidemic agents [14-17].

Alderman et al. [18] analyzed data from the Coronary Artery Surgery Study to determine the factors associated with progression of NCA disease at 5 years' angiographic follow-up in 314 patients. Diabetes, lesion location, increased cholesterol level and complex lesion morphology were correlated with progression of atherosclerotic plaques. In this study it was found that progress of the disease in NCA was inversely related to blood pressure. These patients were under treatment for hypertension with calcium channel blockers, angiotensin-converting enzyme inhibitors and beta-blockers. It may be that some of these drugs slow down the pace of atherosclerosis. This finding was contrary to what was found in the grafted vessels. Thus $59.3 \%$ of SVGs were blocked or severely stenosed in hypertensives when compared to $39.7 \%$ of nonhypertensives over a 6-year period. Again we conclude that SVGs are more prone to atherosclerosis among hypertensive subjects. 
Diabetes was associated with significantly more disease progression in NCA (88.1 vs. $71.4 \% ; \mathrm{p}<0.05)$. On the other hand, there was no significant difference in disease progress in grafted vessels between diabetics and nondiabetics ( 47.4 vs. $52.4 \%$ ). The long-term result of $\mathrm{CABG}$ in females was similar to males. Although women were older than men $(60 \pm 8$ years vs. $56 \pm 9)$ and had greater prevalence of diabetes (57 vs. $47 \%$ ) and hypertension (61 vs. $46 \%$ ), yet the rate of progress of the disease was not significantly different (years since CABG to significant symptoms for females $7.5 \pm 5.5$ vs. $8 \pm 5$ for males).

Atherosclerosis of SVG and NCA appears to have different prognosis. For patients undergoing catheterization 5 years or more postoperatively, mortality in the subsequent 2 years is $30 \%$ for patients with a stenotic vein graft to LAD compared to $3 \%$ in those with a stenosed native vessel [19]. Thus when the disease was mainly in LAD vein graft, repeat CABG, when feasible, was recommended. As mentioned, survival of patients after repeat CABG was good for 23 out of 24 patients with 1 operative mortality and with less angina in $66 \%$. Patients with progress in narrowing of NCA were recommended to have PTCA. Two patients in our study had PTCA for distal SVG narrowing and 1 for distal LIMA anastomotic narrowing. In 36 other patients PTCA was done for NCA. Angioplasty was effective in reducing anginal symptoms by I-III (with only repeat PTCA in 3 patients) classes in $91 \%$. Short-term results of PTCA were quite satisfactory even though long-term results of graft PTCA is less when compared to PTCA of NCA [20]. Among our patients, there was 1 death and no cases with heart failure for the period of follow-up, with significant improvement of anginal class at the time of follow-up.

In patients for whom repeat $\mathrm{CABG}$ or PTCA were not feasible because of diffuse disease $(48 \%$ of the total cohort) half improved I-II angina classes with intensification of medical treatment. Three patients were severely symptomatic and did not respond at all to medical treatment and had to be referred for transmyocardial laser revascularization. After a 1-year follow-up they are at worst in angina class I. In our study $20 \%$ had repeat $\mathrm{CABG}, 48 \%$ had medical treatment and $32 \%$ had PTCA. It would appear that if the patient's disease process led to PTCA his chances for symptomatic relief were the best. Compared to others [19], repeat CABG was resorted to much less frequently in our series. Nonetheless, there was no worsened outcome for adopting this conservative approach of surgical option.

In conclusion, symptomatic patients with post-CABG are not at high risk of death or congestive heart failure. These patients should be catheterized fairly promptly. Based on their coronary anatomy and disease burden in their grafted vessels they could benefit from PTCA, repeat CABG or intensive medical treatment. Amongst the three options, those who could have PTCA had better amelioration of their symptoms.

\section{Acknowledgment}

We thank Mr. Shahid Alam Khan for his help in the preparation of the manuscript. 


\section{References}

1 Bourassa MG: Fate of venous grafts: The past, the present and the future. JACC 1991;17:1081-1083.

2 Lytle BW, Loop FD, Cosgrove DM, Ratliff NB, Easley K, Taylor PC: Long term (5 to 12 years) serial studies of internal mammary artery and saphenous vein coronary artery bypass grafts. J Thorac Cardiovasc Surg 1985;89:248-258.

3 Fitzgibbon GM, Leach AJ, Kafka HP, Keon WJ: Coronary bypass graft fate: Long term angiographic study. JACC 1991;17:1075-1080.

4 Cameron AAC, Davis KB, Rogers WJ: Recurrence of angina after coronary artery bypass surgery: Predictors and prognosis (CASS registry). JACC 1995;26:895-899.

5 Lytle BW, Loop FFD, Taylor PC, Goormastic M, Stewart RW, Novoa R, Mc Carthy P, Cosgrove DM: The effect of coronary reoperation on survival of patients with stenonis in saphenous vein bypass grafts to coronary arteries. J Thorac Cardiovasc Surg 1993;105:605-614.

6 Gordin CM, Campeau L, Lesperance J, Enjalbert M, Baurossa MG: Comparison of late changes in internal mammary artery and saphenous vein grafts in two consecutive series of patients 10 years after operation. Circulation 1984;70(suppl 1):208212.

7 Puga J: The use of internal mammary artery for revascularization of the left anterior descending coronary artery. Eur Heart J 1995;16:21-25.
8 Noyez L, Van del Werf T, Remmen GHJ, Kann GL, Lacquet LK: Importance of the internal mammary artery for coronary bypass grafting in patients aged 70 years or more. Am J Cardiol 1995; 75:734-736.

9 Cameron AAC, Green GE, Brogno DA, Thoronton $\mathrm{J}$ : Internal artery grafts: 20 years clinical follow-up. JACC 1995;25:188-192.

10 Campeau L: Letter to editor. Circulation 1976;54:522.

11 Chen L, Chester MR, Redwood S, Huang J, Leathan E, Kaski JC: Angiographic stenosis progression and coronary events in patients with 'stabilized' unstable angina. Circulation 1995;91:2319-2324.

12 Chester MR, Chen L, Tousoulis D, Poloniecki J, Kasaki JC: Differential progression of complex and smooth coronary stenosis with individuals with stable coronary artery disease. JACC 1995;25:837-842.

13 Campeau L, Enjalbert M, Lesperance J, Bourassa MG, Kwiterovich P Jr, Wacholder S, et al: The relation of risk factors to the development of atherosclerosis in saphenous vein bypass grafts and progression of disease in the native circulation: A study 10 years after aortocoronary bypass surgery. N Engl J Med 1994; 311:1329-1332.

14 Blankenhorn DH, Nessim SA, Johnson RL, San Marco ME, Azen SP, Cashin-Hempill L: Beneficial effects of combined colestipol-niacin therapy on coronay atherosclerosis and coronary venous bypass grafts. JAMA 1987;257:3223-3240.
15 Daid H, Yokoi H, Miyano H, Mokuno H, Satoh H, Kottke TE, Hosoda Y, Yamaguchi H: Relation of saphenous vein graft obstruction to serum cholesterol level. JACC 1995; 25:193-197.

16 Yusuf S, Anand S: Cost of prevention: The case of lipid lowering (editorial). Circulation 1996;93: 1774-1776.

17 Barbir N, Hunt BJ, Galloway D, Taylor A, Ilsley C, Mitchell A, Yacoub M: A randomized pilot trial of low dose combination of lipid lowering therapy following coronary artery bypass grafting. Clin Cardiol 1994;17:59-64.

18 Alderman EL, Corley SD, Fisher LD, Chaitman BR, Faxon DP, Foster ED, Killip T, Sos JA, Bourassa MG: Five year angiographic followup of factors associated with coronary artery disease in coronary artery surgery study (CASS): CADD participating investigations and staff. JACC 1993;22:1141-1154.

19 Lytle BW, Loop EF, Taylor PC, Simpfendorfer C, Kramer JC, Ratliff NB, et al: Vein graft disease: The clinical impact of stenosis in saphenous vein bypass graft to coronary arteries. J Thorac Cardiovasc Surg 1992;103:831-840.

20 deFeyter PJ, Van Suylen RJ, de Jaedere PPT, Topol EJ, Serruys PW: Balloon angioplasty for the treatment of lesions in saphenous vein bypass graft. JACC 1993;21:1539_ 1549. 